\title{
Changes in Illegal Behavior During Emerging Adulthood
}

\author{
Badiah Haffejee \\ Jamie Rae Yoder \\ Kimberly Bender
}

\begin{abstract}
Emerging adulthood marks a critical developmental juncture during which some individuals disengage from the illegal behavior of their adolescence while others continue to use substances and commit crimes. While risk factors for delinquency during adolescence are well studied, factors that influence persisting or desisting from illegal activities during emerging adulthood have not been fully explored. This mixed methods study utilizes a sample of college students aged 18-25 ( $N=74)$ and examines factors differentiating those who abstained from illegal behaviors, desisted from illegal behaviors, and persisted in illegal behaviors. Multinomial logistic regression models indicated peers offending and hours spent studying predicted desisting and peers offending predicted persisting (compared to the abstaining group). Three qualitative themes: family and peer bonds, morals and values, and fear of consequences further explained factors influencing emerging adults' persisting and desisting choices. Implications for social work practice are explored.
\end{abstract}

Keywords: Desistance, emerging adults, illegal behavior, college students, substance use

Many adolescents across cultures report committing some form of criminal or delinquent behavior (Uggen \& Massoglia, 2002). As adolescents age into emerging adulthood, however, they face a critical developmental period in which some will experience maturity and positive behavioral changes (Arnett, 2000) often desisting from illegal behaviors (Griffin, 2006; Mulvey et al., 2004) while others will continue to use substances and commit crimes (Arnett, 2000, 2005; Tucker, Ellickson, Orlando, Martino, $\&$ Klein, 2005). Although substantial research has identified risk and protective factors for adolescent delinquency, relatively little is understood about the factors influencing emerging adults' choices to desist (stop) or persist (continue) illegal activities (Laub \& Sampson, 2001; Maruna, 1999). Furthermore existing work on desistance typically includes samples of offenders who have, at some point, been involved with the criminal justice system (Maruna, 1999; Uggen \& Kruttschnitt, 1998). The current study aims to add to the current literature by examining the factors associated with continued engagement in or desistance from illegal behaviors (i.e., crime and substance use) among emerging adults enrolled in a higher education institution.

\section{Emerging Adulthood}

Emerging adulthood is described as the developmental stage between the ages of 1825 characterized by "finding one's self", instability, and "feeling in-between" (Arnett, 2004, 2005). This period is not classified as adolescence nor young adulthood (Arnett, 2000). Transitioning to adulthood looks drastically different than it did fifty years ago. It

Badiah Haffejee, MSW, and Jamie Rae Yoder, MSW, are Doctoral Students, and Kimberly Bender, Ph.D., is an Assistant Professor, all at the University of Denver Graduate School of Social Work.

Copyright (C) 2013 Advances in Social Work Vol. 14 No. 2 (Fall 2013), 458-476 
has been extended to last longer, with milestones (such as marriage and parenting) delayed until individuals are much older (Arnett, 2000, 2005). Societal evolution, pressure to complete educational endeavors, and identity exploration are all reasons for the evolving definition of emerging adulthood (Arnett, 2000, 2005).

Emerging adults can be separated into subgroups; one important distinction is involvement in higher education during emerging adulthood (Arnett, 2007). Many young adults entering emerging adulthood strive to obtain skills to compete in the global economy by obtaining postsecondary education, with $60 \%$ of emerging adults who graduate high school seeking higher education (Hamilton \& Hamilton, 2006). While young adults who do not go to college are struggling to find employment and survive financially, youth entering college are also inundated with a host of life changes and attempt to adapt their behaviors to fit their new life and freedom style (Arnett, 2007). Some of these transitions include an increased work and study load, decreased sleep, new stress and pressures to perform to a higher standard, and an unfamiliar sense of autonomy (Lev Ari \& Shulman, 2012).

As the notion of emerging adulthood has changed, behaviors of youth as they enter this stage also continue to change (Arnett, 2000, 2005). So, while previously emerging adulthood referred to a tapering off of illegal behavior, more recently, emerging adulthood has been recognized as a vulnerable period during which youth often extend their criminal or delinquent activity (Arnett, 2004, 2005; Tucker et al., 2005) and continue to engage in substance use behaviors such as marijuana use, smoking, and binge drinking (Tucker et al., 2005). Research has demonstrated how alcohol use, in particular, progressively increases during emerging adulthood (Xue, Zimmerman, \& Cunningham, 2009), with high rates of alcohol abuse and dependence during this time (Arnett, 2005). Also notable during this developmental period is the high prevalence of non-violent and violent arrest rates (Piquero, Brame, Mazerolle, \& Haapanen, 2002). Although collegeinvolved and uninvolved emerging adults may both be at risk for criminal behaviors and substance use, the reasons for these behaviors may differ. Long-term unemployment and basic educational achievement are predictors of offending behavior more generally (Aaltonen, Kivivuori, \& Martikainen, 2011), while college students may be acclimating to a new lifestyle characterized by new demands and increased stress and pressure (Goldman et al., 2002; Lev Ari \& Shulman, 2012; White, Labouvie, \& Papadaratsakis, 2005).

Several researchers attribute these changes and increases in high-risk behavior to the "college experience" (Bachman, Wadsworth, O’Malley, Johnston, \& Schulenberg, 1997; Chassin, Pitts, \& Prost, 2002; Goldman, Boyd, \& Faden, 2002; White et al., 2005). The insecurities of adapting to college life, including the susceptibility to new peer influences, place youth at risk for engaging in substance use (Schulenberg \& Maggs, 2001). Arnett (2005) further suggests that this developmental stage provides more freedom and less social control than high school years. Through this transitional period, more youth are without parental supervision; this newfound autonomy is associated with peaks in substance abuse and alcohol consumption (Bachman et al., 1997; Chassin et al., 2002; White et al., 2006). 


\section{Factors Associated with Illegal Behavior}

Life course criminologists theorize that age and maturation are not one and the same (Laub \& Sampson, 2003). While not all adolescents desist from illegal behavior as they become young adults, those who mature (i.e., experience the commitment and stability associated with developmental turning points such as marriage and employment) leave adolescence behind and reduce their criminal behavior (Laub \& Sampson, 2003). Thus, as individuals mature, social consequences of criminal engagement are deterrents and desistance from illegal behavior becomes normative. Persistent criminals, on the other hand, often follow more antisocial trajectories due to heightened environmental and biological risk factors (Laub \& Sampson, 2003).

In predicting youth engagement in illegal behavior, school success plays a critical role. Researchers have highlighted certain risk factors that can emerge in grade school or high school but have impacts on delinquency as youth reach emerging adulthood (Falls et al., 2011). Factors such as poor academic achievement (Katsiyannis, Ryan, Dalun, \& Spann, 2008; Maguin \& Loeber, 1996), lack of social bonds to school staff, and low attachment to school while youth are in high school have been associated with delinquency (Felson \& Staff, 2006). Longitudinal research also finds low academic aspirations and poor motivation for schoolwork predict youths' substance use (Bachman, Staff, O’Malley, Schulenberg, \& Freedman-Doan, 2011). Youth who cause classroom disruptions are also more likely to engage in substance use (Wong, 2008).

In addition to academic factors, much of the research on illegal behavior has identified association with delinquent peers as a significant correlate of problem behavior (Haynie, 2001; Rebellon, 2006; Warr, 2002). These studies suggest that youth continuously attempt to maintain a "delinquency balance" with their closest friends by changing their behaviors to match to their friends' behaviors rather than altering their friendships to fit their own behavior (McGloin, 2009). Negative peer relationships and associations may also increase youths' willingness to engage in substances (Ferguson, Swain-Campbell, \& Horwood, 2002), and peer influences continue to predict substance use into emerging adulthood (Monahan, Steinberg, \& Cauffman, 2009). Individuals who desist from illegal behavior in early adulthood, on the other hand, are more likely than those who persist to report pro-social bonding with peers (Clingempeel \& Henggeler, 2003).

\section{Research Questions}

The current study aims to build on the current literature by examining the critical transition to emerging adulthood among a sample of college students. The study seeks a better understanding of why some emerging adults desist while others persist in regards to illegal behavior (crime and substance use). This study uses quantitative and qualitative methods to identify factors differentiating emerging adults who never engaged in illegal behavior (abstainers), who committed illegal behaviors but have stopped (desisters), and who continue to commit illegal behaviors (persisters). Specifically, this study asks two research questions: 1) How do college students qualitatively describe their reasons for and against engaging in illegal behavior during emerging adulthood? 2) What 
quantitative risk and protective factors are associated with illegal behavior among college students?

\section{Methods}

\section{Procedures}

Data were collected, with institutional review board approval, through confidential questionnaires completed by a sample of college students $(\mathrm{N}=74)$ at one university on the West coast of the United States. Students were invited to participate in a study asking them about their involvement in illegal behaviors such as minor thefts, vandalism, and substance use. They were informed the study would take approximately 20 minutes and they could complete the questionnaire in class. Following informed consent, students were given the opportunity to voluntarily participate in the survey or leave the classroom. The survey was administered using pencil and paper, took approximately 20 minutes to complete and did not involve student compensation. One hundred percent of the students sampled agreed to participate.

\section{Sample}

Participants consisted of emerging adults, between the ages 18-25 years of age, attending a public university located in an urban area in the Western United States. The researchers sought a purposive sample of full-time undergraduate students attending courses in the College of Letters and Sciences (Sociology, statistics, \& English) with the goal of accessing the largest college with racially/ethnically and academically (i.e., freshman through senior) diverse student groups.

\section{Measures}

The researcher-developed concurrent qualitative and quantitative measure was piloted with 40 students in two full-time undergraduate classes prior to the current study. The measure was given to students to determine the usefulness of the questions and to see if we would achieve the desired response rate of at least 70 percent. A response rate of $100 \%$ was achieved and the measure took approximately 20 minutes to complete. After completing the questionnaire, the participants were invited to provide feedback. The participants made the determination that the open-ended question that allowed participants to "tell their story" was too complex; the question included several subquestions for which the respondents failed to provide detailed answers. To address this feedback, prior to administering the measure with the study sample, the instrument was revised for clarity.

The data collection instrument used in this study contained demographic questions as well as qualitative and quantitative questions regarding participants' experiences with illegal behavior. Demographics included age, gender $(0=$ female, $1=$ male $)$, ethnicity (1=African American, 2=Asian, 3=Caucasian/White, 4=Latino/a, Chicano/a, Hispanic, $5=$ other), parent's education ( $1=$ did not complete high school, $2=$ graduated high school, $3=$ some college, $4=$ completed college), household income (1=less than 12,000, 
$2=12,000-24,999,3=5,000-50,999,4=51,000-100,999,5=101,000-250,000)$, and selfidentified social class (1=working class, $2=$ lower middle-class, $3=$ upper middle-class, 4=upper-class).

\section{Qualitative Measures}

To capture qualitative information from emerging adults regarding their level of engagement in illegal behaviors, qualitative questions were designed with sensitivity in an attempt to give participants an opportunity to share their unique perspectives and give voice to their stories and experiences (Padgett, 2008). Participants were asked a series of three qualitative questions to better understand their involvement in illegal behaviors. A short statement introduced the topic of illegal behavior during emerging adulthood: "Research from the last fifty years data indicates that many, if not the majority of people from a variety of cultures commit some form of illegal behavior in their adolescence. For many people these illegal behaviors involve minor thefts, vandalism, or banned drugs. Yet, many youth also abandon these activities at some point." The participants were then asked, "Thinking about your own involvement in illegal behavior, please describe the factors, events or circumstances that encouraged you to stop offending." The second question focused on persistence and asked students, "If you have not stopped, please explain the reasons why you think you continue." The third part of the question focused on abstaining and asked, "If you have never engaged in illegal behavior (traffic offenses such as speeding are not crimes) please outline the factors that you think contributed to your decision." These qualitative answers were later quantified to create a dependent variable labeled illegal behavior described in greater detail below.

\section{Qualitative Data Analysis}

Analysis began by reading the students' answers to the three open-ended questions about involvement in illegal behavior. Raw data was then "pre-coded" (Layder, 1998) by highlighting rich words, short phrases, and significant quotes directly from the respondents' answers to begin to organize and categorize the data (Saldana, 2009). This method of In-Vivo Coding was used to keep the data rooted in the participants' own language and to honor their "stories" (Saldana, 2009).

The second type of coding, structural coding, was used to identify patterns/themes in the way abstainers, persisters, and desisters defined and interpreted their experiences (Saldana, 2009). Two authors completed this analysis and emerging themes were coded paying special attention to the social meaning of student responses (Saldana, 2009). This form of analysis facilitated an understanding of the students' identities and the social meaning of the language they used to describe their offending and abstaining behavior. It is through the respondents' language about themselves and their social norms that it became clear how abstaining, desistance, and persistence behaviors occur. 


\section{Quantitative Measures}

\section{Dependent Variable: Illegal Behavior}

For the purposes of this study, desistance is defined as a termination from illegal behavior among individuals who had once engaged in illegal behavior (crime or substance use). Persistent offending is defined as continued participation in illegal activities. Abstaining refers to the absolute abstinence from illegal behavior. It was imperative that there be a conceptual link between the quantitative and qualitative measures. The students' written responses to three predesigned qualitative questions were collapsed to create one quantitative categorical variable labeled illegal behavior. Participants who discussed reasons they had never committed illegal behaviors were labeled "abstainers", respondents who described why they had stopped their illegal behaviors were labeled "desisters", and respondents who explained why they continue to engage in illegal behaviors were labeled "persisters". This dependent variable illegal behavior was coded with three categories $(0=$ abstaining, $1=$ desisters, and $2=$ persisters $)$.

\section{Independent Variables}

Independent variables were selected for inclusion in this study based on previous research on risk and protective factors for delinquency more broadly, and, although more limited, on existing research on illegal behaviors during emerging adulthood.

School Engagement. Four questions measured the broad area of school engagement. These questions included: "How important is getting good grades?" (1= not important at all, $2=$ not very important, $3=$ somewhat important, $4=$ very important); "How likely are you to achieve your educational goals?" $(1=$ not likely at all, $2=$ not very likely, $3=$ somewhat likely, $4=$ very likely); "How many hours do you spend studying per week?" $(1=0-6,2=7-13,3=14-20,4=$ more than 20$)$; and "How many hours per week do you work at a paid job?" $(1=0-10,2=11-20,3=21-30,4=31-40,5=$ more than 40$)$.

Delinquent Peers. To assess peer influence on illegal behavior, participants were asked: "What proportion of your close friends regularly breaks the law (not including traffic offenses)?" Delinquent peers were measured ( $1=$ none, $2=$ few, $3=$ some, $4=$ most, $5=$ all).

Social Bonds. Two indicators of adolescent social bonds were included. The first question asked respondents how often they spent time with parents or siblings $(1=$ never, $2=$ holidays, $3=$ weekends, $4=$ everyday). The second question inquired about spending time with a romantic partner and was measured $(1=$ not important at all, $2=$ not very important, $3=$ somewhat important, $4=$ very important $)$.

\section{Quantitative Data Analysis}

Raw data from the interviews were entered into SPSS (version 18.0). Tests for normality were conducted, and assumptions were met. Descriptive analyses were conducted to illustrate sample characteristics using mean and standard deviation, frequency, and percentages. Prior to running bivariate analyses, the variable Parent's 
Education was dummy coded to account for insufficient number of cases per category and measured $(0=$ did not complete college, $1=$ completed college). Class was similarly dummy coded to indicate ( $0=$ other, $1=$ upper/middle class). Bivariate analyses (chisquare tests and one-way ANOVAs) were conducted to determine whether independent variables and demographic variables differed across the three categories of the dependent variable (abstaining, desisting, and persisting groups).

Variables with significant bivariate relationships to the dependent variable were entered in multivariate analyses. To do so, categorical demographic variables were dummy coded. Due to the low power afforded in this relatively small sample, Ethnicity was dummy coded to indicate $(0=$ other, $1=$ White or Caucasian $)$. While controlling for demographic characteristics (age, gender, ethnicity (white), parent's education, household income, and social class) a multinomial logistic regression model was analyzed, regressing illegal behavior on independent variables that were statistically significant at the bivariate level (hours spent studying per week and the proportion of friends committing crimes). The multinomial logistic regression model examined the likelihood of the emerging adults being in the desisting and persisting group compared to the abstaining (reference) group.

\section{Results}

\section{Sample Characteristics}

As shown in Table 1, participants $(N=74)$ were primarily females $(73 \%)$. The mean age of the sample was 21 years of age $(\mathrm{SD}=2.3)$, with the majority of the sample $(95.9 \%)$ between 18 and 25 years of age. This sample was ethnically diverse, with $8.1 \%$ selfidentified as African American, 35.1\% identified as Asian, 32.4\% identified as Caucasian, $12.2 \%$ identified as Hispanic, and $12.2 \%$ identified as other. The sample demonstrated varying levels of illegal behavior; approximately $38 \%$ of the sample indicated they had always been abstaining, 38\% of the sample indicated they were desisters (had once participated in illegal behaviors but had stopped) and $24 \%$ of the sample indicated they were persisters (continued to participate in illegal behaviors).

\section{Qualitative Results}

Several themes emerged across persisting, desisting, and abstaining emerging adults. In discussing their rationales for whether or not they engaged in illegal behavior, all three groups discussed: social bonds with family and peers, internalized morals and values, and a fear of consequences for their behavior.

\section{Social Bonds and Behavioral Norms within Family and Peer Groups}

Persisters frequently mentioned that their connections to peers and family members heavily influence their decision to persist in illegal behaviors. These participants shared that, not only is engaging in illegal behavior (particularly substance use) common, it is an important part of the college experience. Moreover, it provides emerging adults a "sense 
of belonging" and "connectedness to a larger group." One respondent's statement exemplified the importance of her bond to her social environment as she described:

Table 1. Sample Characteristics and Differences between Abstaining, Desisting, and Persisting Groups

\begin{tabular}{|c|c|c|c|c|c|c|c|c|c|}
\hline & \multicolumn{2}{|c|}{$\begin{array}{c}\text { Total } \\
\text { Sample }\end{array}$} & \multicolumn{2}{|c|}{ Abstaining } & \multicolumn{2}{|c|}{ Desisting } & \multicolumn{2}{|c|}{ Persisting } & \multirow[t]{2}{*}{$F$ or $\chi^{2}$} \\
\hline & freq & $\%$ & freq & $\%$ & freq & $\%$ & freq & $\%$ & \\
\hline Gender & & & & & & & & & $\chi^{2}=2.5$ \\
\hline Male & 20 & 27 & 5 & 25 & 8 & 40 & 7 & 35 & \\
\hline Female & 54 & 73 & 23 & 42.6 & 20 & 37 & 11 & 20.4 & \\
\hline Ethnicity & & & & & & & & & $\chi^{2}=14.6$ \\
\hline $\begin{array}{l}\text { African } \\
\text { American }\end{array}$ & 6 & 8.1 & 1 & 16.7 & 5 & 83.3 & 0 & 0 & \\
\hline Asian & 26 & 35.1 & 13 & 50 & 9 & 34.6 & 4 & 15.4 & \\
\hline Caucasian & 24 & 32.4 & 9 & 37.5 & 5 & 20.8 & 10 & 41.7 & \\
\hline Hispanic & 9 & 12.2 & 3 & 33.3 & 5 & 55.6 & 1 & 11.1 & \\
\hline Other & 9 & 12.2 & 2 & 22.2 & 4 & 44.4 & 3 & 33.3 & \\
\hline Parent's Education & & & & & & & & & $\chi^{2}=1.0$ \\
\hline Did not & 36 & 48.6 & 14 & 38.9 & 15 & 41.7 & 7 & 19.4 & \\
\hline $\begin{array}{l}\text { Graduate } \\
\text { College }\end{array}$ & & & & & & & & & \\
\hline $\begin{array}{l}\text { Graduated } \\
\text { College }\end{array}$ & 38 & 51.4 & 14 & 36.8 & 13 & 34.2 & 11 & 28.9 & \\
\hline Class & & & & & & & & & $\chi^{2}=4.4$ \\
\hline Upper-Middle & 26 & 35.1 & 8 & 30.8 & 8 & 30.8 & 10 & 38.5 & \\
\hline \multirow[t]{2}{*}{ Other } & 48 & 64.9 & 20 & 41.7 & 20 & 41.7 & 8 & 16.7 & \\
\hline & Mean & $S D$ & Mean & $S D$ & Mean & $S D$ & Mean & $S D$ & \\
\hline Importance of Grades & 2.7 & .5 & 2.6 & .7 & 2.8 & .4 & 2.7 & .5 & $F=.9$ \\
\hline $\begin{array}{l}\text { Likely to Achieve } \\
\text { Educational Goals }\end{array}$ & 2.6 & .5 & 2.6 & .5 & 2.6 & .6 & 2.6 & .5 & $F=.1$ \\
\hline $\begin{array}{l}\text { Proportion of Friends } \\
\text { Regularly Break the Law }\end{array}$ & 1.5 & 1.0 & .9 & .7 & 1.6 & .9 & .2 & 1.0 & $F=14.9^{* * *}$ \\
\hline Time spent with Parents & 2.5 & .6 & 2.6 & .6 & 2.5 & .6 & 2.4 & .6 & $F=.5$ \\
\hline Time spent with Partner & 5.1 & 2.7 & 5.2 & 2.7 & 5.0 & 2.7 & 5.1 & 2.7 & $F=.1$ \\
\hline Age & 20.9 & 2.3 & 20.9 & 1.4 & 20.7 & 2.0 & 21.3 & 3.6 & $F=1.4$ \\
\hline $\begin{array}{l}\text { Hours Spent Studying per } \\
\text { Week }\end{array}$ & 1.1 & .8 & 1.5 & .7 & .8 & .8 & 1.0 & .6 & $F=6.6^{* *}$ \\
\hline $\begin{array}{l}\text { Hours per Week Worked } \\
\text { at a Paid Job }\end{array}$ & .7 & .8 & .8 & 1.0 & .6 & .7 & .6 & .7 & $F=.6$ \\
\hline
\end{tabular}

$* p<.05 * * p<.01 * * * p<.001$; Note: $\chi^{2}$ analyses for ethnicity failed to meet minimum cell count assumptions, with a few cells including 0 participants; these frequencies are included in the table to provide the reader with a general sense of proportions and trends across ethnic groups. 
It is part of the college culture. As a sorority, drinking is encouraged, if not mandatory. At times I feel it is necessary to drink to function socially...drinking is a big part of my social scene and it's not bad...smoking marijuana...it's a part of the social scene. I am in college, what else is there to do?

Desisters, on the other hand, reflected upon family norms against illegal behavior more so than did persisters. Desisters cited shaming, hurting, and disappointing their parents as motivators to desist from their illegal behavior. One participant simply said, "My parents, as poor as they were... strongly believed in honesty. I highly respect them and did not want to make them ashamed of me. I was going to lose them if I continued [to commit illegal behavior]." A second participant echoed these sentiments and described coming to the realization that her behavior was no longer "cool," instead she "was actually losing the respect" of her parents. Social bonds with prosocial family members therefore encouraged participants to desist.

Abstainers, described social ties with their family (i.e., parents/caregivers) members in much more detail compared to either persisters or desisters. They emphasized positive parenting, being raised the "right way", including "strict parents setting rules," consequences, and stability in the home to reinforce prosocial behavior. Abstainers discussed not only being loved, but also being monitored and guided by parents. They also described social bonds to peer groups that reject illegal behavior. One participant noted:

I have a stable home life with two loving parents that have always spoken to me about the pitfalls of committing crimes. For this reason I have never wanted to commit a crime. I have also never felt pressured by my friends. I always knew that I wanted to be successful so I chose friends that also wanted to be successful.

Another participant aptly said, "When I saw some of my friends engage in stuff that would get them into trouble, I stopped hanging out with them." Their decision to refrain from illegal behavior appeared to be due to their strong familial ties and a lack of association with deviant peer groups.

A vital feature that emerged across three categories is parents. For abstainers, strong bonds and ties to parents including parental involvement influenced their decision not to engage in illegal behavior. For persisters, the lack of parental involvement and supervision (weaker bonds to parents) aligned with greater influence of negative peer groups and contributed to their involvement in illegal behavior. Because the emerging adults in this study were no longer under continual parental surveillance, the influence of prosocial bonds with parents must have been internalized for abstainers. For persisters, they may have estimated that they could conceal their involvement from disapproving others or lacked bonds with individuals who disapprove. Desisters who made the decision to desist from illegal behavior spoke about the shame, guilt, or embarrassment that antisocial behavior caused, particularly in their relationships with their parents. 


\section{Morals and Values}

Participants in all three groups described their perspectives of right and wrong or moral behavior in answering questions about their illegal behaviors. Persisters described illegal behavior by discussing a sense of right and wrong, but they held the perspective that their behavior was socially acceptable. They recognized that society may label their behaviors as deviant, but they argued their behavior is benign because they were not causing harm to others. One respondent said, "For the most part I have stopped small crimes, however, I do continue to violate laws or rules [about drinking and drug use] that I feel cause no danger to me and others. I am not hurting anyone." Actually, persisters articulated an independent even defiant attitude toward authority, valuing their own autonomy and rebellion against mainstream rules. A second respondent explicitly remarked:

I still smoke marijuana. I don't consider marijuana an illegal drug. I don't believe marijuana use (which is probably the most illegal thing I have done) is actually a crime...making it a crime and enforcing certain laws only encourages and perpetuates under-age substance use.

Desisters appeared focused on shame and guilt for their behavior. Often this shame and guilt grew out of pain they may have caused others rather than a sense that they were doing "the wrong thing." According to one participant, "The last time I did it, I felt horribly guilty even though it was a small item...[I] felt guilty and [I] was afraid to return to the store." Desisters seemed to be concerned with disappointing others who would view their behavior as wrong while abstainers seemed to have internalized these valueswhich kept them from engaging in illegal behavior. Abstainers explained that "high morals and values instilled" by their parents and "strong moral religious beliefs positively affected" their choices not to become involved in illegal behavior. Internalization of that sense of right and wrong (morals) seemed weaker among desisters who were accepting of illegal behavior but worried about parents or other people disapproving.

\section{Fear of Consequences}

A fear of consequences (or lack thereof) for committing crimes or using substances played an important role in influencing emerging adults' choices to engage in illegal behavior. Persisters typically did not fear consequences for their behavior. Past consequences, namely a citation for "Minor In Possession (MIP)" and "always getting into trouble with campus police," were viewed as insignificant. Often, participants discussed committing behaviors that went unnoticed and thus had little consequence for them or others. In fact, several persisters discussed the rewards of illegal behavior, feeling "high" and thrilled at the adrenaline "rush" of committing illegal acts. One participant described this overwhelming excitement saying, "I stole a huge cardboard sign from behind the movie theater...I did it, $50 \%$ for the acquisition of the sign and $50 \%$ for the thrill of it. It was a huge sign." Defying authority was a risk, but it was viewed as an exciting risk well worth any minor consequence or punishment.

Desisters, on the other hand, frequently discussed a fear of consequences for their behaviors. Several discussed their own or their friends' arrests. These consequences were 
viewed as serious and detrimental. A clear line was drawn for desisters as they approached age 18. One respondent wrote, "Once I turned 18, I realized that my behavior had more serious consequences, particularly in a legal sense. Before I was 18, committing minor crimes did not seem like a big deal, especially since others around me engaged in the same behaviors." Another participant wrote, "I stopped when I was 18 for fear of going to jail." They realized the legal consequences of their behavior were amplified as adults, and thus chose to make changes to avoid these more serious sanctions.

Abstainers discussed weighing the costs (i.e., being caught, having a criminal record, social stigma) and benefits (limited excitement and temporary fun) and recognized early on that deviant behavior was not worth the costs. This finding fits well within the context of Social Exchange Theory which suggests that individuals choose behaviors based on a comparison of alternatives and a weighing of the relative costs and benefits of each option (Homans, 1958). Importantly, the determination of costs and benefits is subjective and individualized (McDonell, Strom-Gottfried, Burton, \& Yaffe, 2006). Costs, for abstainers, were broad and far-reaching compared to the more immediate costs described by desisters. While desisters were concerned about arrest and prosecution, abstainers

considered their future goals and career aspirations. They appeared to consider themselves as taking a different path through life that did not leave room for illegal behaviors. Abstainers, unlike the other two groups, also discussed concern for greater society, suggesting they refrained from illegal behavior to protect society as a whole.

\section{Quantitative Results}

\section{Group Differences Across Desisting, Persisting, and Abstaining Emerging Adults}

The results of the one-way ANOVA demonstrated that abstainers, desisters, and persisters differed significantly in their number of hours spent studying per week $(F(2$, $73)=6.6, p=.002$, eta-squared $=.2$, with abstaining students reporting the most studying $(M=1.5, S D=.7)$, followed by persisters $(M=1.0, S D=.60)$, and desisters reporting the least studying $(M=.8, S D=.8)$. Post-hoc analyses using Games-Howell indicated a significant difference in hours studying only between abstaining and desisting students $(p<.01)$.

Furthermore, the results indicated that abstaining, desisting, and persisting students differed significantly in their proportion of friends that regularly broke the law $(F(2,73)$ $=14.9, p<.001$, eta-squared $=.3$ ). Persisters had the greatest number of law-breaking friends $(M=2.3, S D=1.0)$, followed by desisters $(M=1.6, S D=.9)$, and then abstaining participants $(M=.9, S D=.7)$. Scheffe post-hoc tests indicated statistically significant means across all three groups.

\section{Correlates of Illegal Behavior in a Multivariate Model}

The multinomial logistic regression model controlling for age, gender, race and class found that participants' illegal behavior was significantly predicted by the independent variables of interest $\left(\chi^{2}(12)=45.5, p<.001\right)$. As noted in Table 2 , two factors of interest (peers' offending and hours spent studying per week) significantly predicted being in the 
desisting group compared to the abstaining group. Students with greater proportions of peers who offended were nearly three times more likely to be in the desisting group compared to the abstaining group (OR $=2.7, p<.05)$. Students who studied less often were more likely to be in the desisting group compared to the abstaining group $(\mathrm{OR}=.2$, $p<.01$ ). One factor significantly predicted being in the persisting group compared to the abstaining group. Students who reported a greater proportion of peers who offended were significantly more likely to be in the persisting group than the abstaining group $(\mathrm{OR}=5.6$, $p<.001)$.

Table 2. Multinomial Logistic Regression to Predict Desisting and Persisting Compared to Abstaining

\begin{tabular}{lcccc}
\hline \multirow{2}{*}{ Factors } & \multicolumn{2}{c}{ Desisting } & \multicolumn{2}{c}{ Persisting } \\
\hline Hours spent studying per week & $.2 * *$ & $95 \%$ CI & OR & $.1-1.2$ \\
Proportion of peers offended & $2.7 *$ & $1.1-6.2$ & $5.6 * * *$ & $2.1-16.6$ \\
Class (Upper/Middle) & 1.5 & $.3-6.3$ & 2.4 & $.4-13.1$ \\
Ethnicity (White) & .3 & $.1-1.4$ & 1.5 & $.3-7.9$ \\
Gender & 1.3 & $.3-6.6$ & 1.3 & $.2-8.0$ \\
Age & 1.0 & $.7-1.3$ & 1.1 & $.8-1.6$ \\
\hline $\begin{array}{l}\text { Note. Reference category= Abstaining Group; OR= Odds Ratio; } 95 \% \text { CI=95\% confidence interval } \\
* p<.05 * * p<.01 * * * p<.001\end{array}$ & & & \\
\hline
\end{tabular}

\section{Discussion}

This study sought a better understanding of the factors that influence desistance and persistence of illegal behaviors during emerging adulthood. A key finding was the significant influence of peers on emerging adults' participation in crime and substance use. Emerging adults who described their peer networks as consisting largely of friends who participate in illegal behaviors were much more likely to have committed illegal acts than those who were bonded more closely with their families and prosocial peer groups. While previous research has documented the strong influence of peers on adolescent delinquency (Havighurst, 1987; Kandel, 1985; Steinberg, 2008), this study extends this work by acknowledging peers' continued importance into individuals' early twenties. In fact, emerging adults looked similar to youth in their descriptions of peers' influencing behavior, particularly when it related to substance use.

The evolving notion of what it means to be an emerging adult may influence behaviors during this stage (Arnett, 2005). In college, emerging adults are confronted with peer influences (Quinn \& Fromme, 2011; White, Fleming, Min, Catalano, \& McMorris, 2008), and social pressures to participate in substances were described as substantial and influential. The college environment may partially explain why peer relationships continue to be a strong indicator of continued engagement in high-risk behaviors (Quinn \& Fromme, 2011; White et al., 2008). Whereas substance use during 
high school may have been viewed as deviant, substance use during college may be more typical or even normative. Furthermore, emerging adults who, in previous generations, may have moved on to employment or marriage during their late teens and early twenties are now more likely to live independently on a college campus surrounded by other emerging adults.

Many students described following parental rules when they lived at home, but abandoned these when they attended college where their peers had a notable negative effect on their decisions. For example, a female student reported that her parents kept her sheltered from mainstream "ideas" and "thinking," and it was easy for her to follow the rules of her home. However, once she entered college, she was negatively influenced and she tried "new" things because her parents were not around. In other words, college culture and the desire to fit in and be a part of the social scene that values independence and substance use may foster illegal behavior.

The influence of peers is more complex than the immediate peer group surrounding emerging adults. Participants described a much longer process, starting when they were children, in which parents provided consistent supervision, monitoring, and implicit lessons of right and wrong which fostered a value for prosocial behavior and friendships. Emerging adults who were raised with loving parents including "strict" rules, structure, and consequences for their behavior were more likely to desist and abstain from illegal behaviors and negative peer groups. Prior studies have documented the instrumental role that positive parenting has on moderating the effects of substance use including several other problem behaviors among high school students (Chassin et al., 2002; White et al., 2006). This study indicates that strong parental bonds and monitoring continue to play a significant role in the lives of emerging adults and their decisions to refrain and abstain from high-risk behaviors. Given that emerging adulthood invites less social control, parental monitoring and involvement, and more freedom than adolescent years (Arnett, 2005; White et al., 2006), this study suggests that parental bonds can strengthen prosocial behaviors in emerging adults and may reduce risk-seeking opportunities for illegal behaviors. Thus, increasing parents' awareness about the importance of parental engagement and monitoring during the emerging adulthood period may be an essential preventative target.

The results also suggest that academic achievement plays a fundamental role in determining illegal behavior of emerging adults. Previous literature suggests that academics may serve as a protective factor against ever initiating criminal behaviors (Jenson \& Fraser, 2006). Academic motivation and dedication appears to continue to play an important role in emerging adults' behavior. Emerging adults entering college are motivated to obtain academic success (Lounsbury, Fisher, Levy, \& Welsh, 2009); this motivation can be attributed to fear of consequences and risks associated with failure (Loughran, Paternoster, Piquero, \& Pogarsky, 2011). That time spent on school work predicted abstaining from illegal behavior compared to desisting, suggests youth who are dedicated students are more likely to come from backgrounds free of crime and substance use. 
The current study also demonstrates that another common element in persistence and desistence is perceived certainty and severity of punishment. Overwhelmingly, persisters mentioned that the punishment imposed for minor offenses is not severe enough; hence they continue to engage in high-risk behaviors. Persisters noted that marijuana and underage drinking should not be illegal. This finding is consistent with previous studies of adolescent samples that find little deterrent effect for perceptions of the costs of punishment (Paternoster, 1989). Conversely, desisters reported a heightened sensitivity to the legal consequences of illegal behavior and the severity of punishment, an awareness that may have resulted from their transition to early adulthood in the eyes of the courts. These results are consistent with the rational choice (Becker \& Murphy, 1988) approach that states that a rational offender calculates the costs and benefits of offending, even though s/he may not have the most complete information. An increase in the expected costs of the illegal behavior or in the rewards for conformity should make illegal behavior less attractive. For those who participated in illegal behavior during adolescence but recently desisted, fear of both legal and relational consequences appeared to influence decisions to stop.

Notable in the desistance process described by this sample are the feelings of fear, guilt, and shame. Many emerging adults reported that they felt guilty or ashamed after their illegal behavior and were sorry that they may have hurt someone, including their parents. This finding is consistent with Sampson and Laub's (1993) age-graded theory of informal social control and their argument that desistance is more likely when offenders change the way they feel about illegal behavior, themselves, and the relationships they have with others.

\section{Limitations}

This study has some evident limitations that need to be addressed. First, the study has a small quantitative sample size, which resulted in reduced power and required several variables to be dichotomized, losing specificity. Ethnicity categories were transformed into a dichotomous form of the variable (white/non-white) for the multivariate analyses. This dilutes the variance found in this variable and future research with larger samples should better investigate the role of ethnic diversity in the relationships found in this study. Secondly, the quantitative outcome of illegal behaviors (abstainers, desisters, persisters) was derived from participants' answers to qualitative questions; although this allowed the participants to describe their illegal behavior in their own words, this may have resulted in less accurate categorization. Independent variables were developed by the researcher, and thus do not have established psychometrics. To the extent that the host university looks similar to other public institutions, our findings may be transferable; however, findings cannot generalize to the broader, non-student population of emerging adults. Third, the reliance on self-reported data of participants poses a drawback to the study design. However in this study, emerging adults self-report was necessary for examining the multiple pathways from illegal activities that involve both social and psychological processes (Laub \& Sampson, 2003). The unique interpretations of the experiences of abstainers, desisters, and persisters were therefore best captured by the mixed-method design and reliance on self-report. Fourth, the cross-sectional design 
leaves the direction of causality ambiguous. That is, it cannot rule out the possibility that participation in illegal behaviors causes one to hang out with antisocial peers and results in less academic motivation.

\section{Implications for Practice}

This mixed methods study has several implications for practice and research. First, the quantitative portion of the study examines the crucial influences of peers and academic motivation in criminal behavioral outcomes. The strong relationship between negative peer associations and illegal behavior suggests that intervening to encourage prosocial and sober opportunities for socializing and relationship building is imperative. Encouraging healthy and adaptive peer relationships through extracurricular clubs and social events, particularly during unstructured evening hours, could be influential in changing college students' behaviors. Clearly, peers play a vital role in shaping attitudes and beliefs among emerging adults. Students who spend more time working on schoolwork during down time are consequently more motivated to do well in school and less inclined to engage in illegal behaviors. Furthermore, from a prevention standpoint, programs to enhance parenting skills, promoting parental limit setting, supervision, monitoring and relationship building with children and adolescents are likely to protect youth from later illegal behavior as adolescents and emerging adults. Parenting skills can also serve to help parents relay the importance of academic motivation and subsequently aid in deterring youth and emerging adults away from illegal behaviors.

\section{Implications for Research}

Although there is a developing body of research on desistance, there is still much to learn. Our understanding of desistance is hampered by a focus on individuals involved with the criminal justice system and other systems of formal social control. Additional research needs to examine desistance among adolescents and emerging adults who have not been institutionalized or sanctioned in some way. Furthermore, the role of parent involvement in influencing emerging adults' illegal behavior should be further investigated as both a potential risk and protective factor, as this role may be changing and may vary greatly across individuals. The important relationships discovered here should also be investigated internationally, as cultural differences may impact emerging adults' behaviors and associated risk factors. From a methodological point, much of what we know about the desistance process is obtained retrospectively, and longitudinal designs are necessary to study the natural evolution of illegal behavior and provide a better description of the processes of offending over time. Greater investigation is also required to understand ecological or neighborhood-level factors influencing desistance. Furthermore, researchers and funding mechanisms need to support further investigation of emerging adulthood as a distinct developmental period, clarifying unique, relevant, and modifiable risk and protective factors for this important group.

Emerging adulthood is a time of great opportunity mixed with heightened vulnerability. As students make decisions regarding their academics and peer groups, it appears they are implicitly placing themselves at varying risk for dangerous behaviors. Prevention and intervention efforts aimed at connecting emerging adults to prosocial 
parents and friends and encouraging their dedication to academics may offer protection for those who aim to abstain or desist from criminal behavior and substance use.

\section{References}

Aaltonen, M., Kivivuori, J., \& Martikainen, P. (2011). Social determinants of crime in a welfare state: Do they still matter? Acta Sociologica, 54(2), 161-181.

Arnett, J. J. (2000). Emerging adulthood: A theory of development from the late teens through the twenties. American Psychologist, 55, 469-480.

Arnett, J. J. (2004). Emerging adulthood: The winding road from the late teens through the twenties. New York, NY: Oxford University Press.

Arnett, J. J. (2005). The developmental context of substance use in emerging adulthood. Journal of Drug Issues, 35(2), 235-253.

Arnett, J. J. (2007). Suffering, selfish, slackers? Myths and reality about emerging adults. Journal of Youth \& Adolescence, 36, 23-29.

Bachman, J. G., Staff, J., O’Malley, P. M., Schulenberg, J. E., \& Freedman-Doan, P. (2011). Twelfth-grade student work intensity linked to later educational attainment and substance use: New longitudinal evidence. Developmental Psychology, 47(2), 344-363.

Bachman, J. G., Wadsworth, K. N., O’Malley, P. M., Johnston, L. D., \& Schulenberg, J. E. (1997). Smoking, drinking and drug use in young adulthood: The impacts of new freedoms and new responsibilities. Mahwah, NJ: Lawrence Erlbaum Associates, Inc.

Becker, G. S., \& Murphy, K. (1988). A theory of rational addiction. American Journal of Sociology, 66, 32-40.

Chassin, L., Pitts, S. C., \& Prost, J. (2002). Binge drinking trajectories from adolescence to emerging adulthood in a high-risk sample: Predictors and substance abuse outcomes. Journal of Counseling and Clinical Psychology, 70(1), 67-78.

Clingempeel, W. G., \& Henggeler, S. W. (2003). Aggressive juvenile offenders transitioning into emerging adulthood: Factors discriminating persisters and desisters. American Journal of Orthopsychiatry, 73(3), 310-323.

Falls, B., Wish, E. D., Garnier, L. M., Caldeira, K, M., O'Grady, K. E., Vincent, K. B., \& Arria, A. M. (2011). The association between early conduct problems and early marijuana use in college students. Journal of Child \& Adolescent Substance Abuse, 20(3), 221-236.

Felson, R. B., \& Staff, J. (2006). Explaining the academic performance-delinquency relationship. Criminology, 44(2), 299-319.

Ferguson, D. M., Swain-Campbell, N. R., \& Horwood, L. J. (2002). Deviant peer affiliations, crime and substance use: A fixed effects regression analysis. Journal of Abnormal Child Psychology, 30(4), 419-430. 
Goldman, M. S., Boyd, G. M., \& Faden, V. (2002). College drinking, what it is, and what to do about it. Journal of Studies on Alcohol, 14, 2-22.

Griffin, P. (2006). Getting out of trouble: The pathways to desistance study. Pennsylvania Progress, 11(4), 1-9.

Hamilton, S., \& Hamilton, M. A. (2006). School, work, and emerging adulthood. In J. J. Arnett \& J. L. Tanner (Eds.), Emerging adults in America: Coming of age in the 21st century (pp. 257-278). Washington, DC: APA Books.

Havighurst, R. J. (1987). Adolescent culture and subculture. In V. B. Van Hasselt \& M. Hersen (Eds.), Handbook of adolescent psychology (pp. 401-412). New York, NY: Pergamon Press.

Haynie, D. L. (2001). Delinquent peers revisited: Does network structure matter? American Journal of Sociology, 41, 355-391.

Homans, G. C. (1958). Social behavior as exchange. American Journal of Sociology, 63, 597-606.

Jenson, J. M., \& Fraser, M. W. (2006). Social policy for children and families: A risk and resilience perspective. Thousand Oaks, CA: Sage.

Kandel, D. B. (1985). On processes of peer influences in adolescent drug use: A developmental perspective. Alcohol and Substance Abuse in Adolescence, 4, 139163.

Katsiyannis, A., Ryan, J. B., Dalun. Z., \& Spann, A. (2008). Juvenile delinquency and recidivism: The impact of academic achievement. Reading \& Writing Quarterly, 24(2), 177-196.

Laub, J. H., \& Sampson, R. (1993). Turning points in the life course: Why change matters to study of crime, Criminology, 31, 301-326.

Laub, J. H., \& Sampson, R. (2001). Understanding desistance from crime. Crime and Justice, 28, 1-69.

Laub, J. H., \& Sampson, R. (2003). Shared beginnings, divergent lives: Delinquent boys to age 70. Cambridge, MA: Harvard University Press.

Layder, D. (1998). Sociological practice: Linking theory and social research. Thousand Oaks, CA: Sage Publications.

Lev Ari, L., \& Shulman, S. (2012). Pathways of sleep, affect, and stress constellations during the first year of college: Transition difficulties of emerging adults. Journal of Youth Studies, 15(3), 273-292.

Loughran, T. A., Paternoster, R., Piquero, A. R., \& Pogarsky, G. (2011). On ambiguity in perceptions of risk: Implications for criminal decision making and deterrence.

Criminology, 49(4), 1029-1061. 
Lounsbury, J. W., Fisher, L. A., Levy, J. J., \& Welsh D. P. (2009). An investigation of character strengths in relation to the academic success of college students. Individual Differences Research, 7(1), 52-69.

Maguin, E., \& Loeber, R. (1996). Academic performance and delinquency. Crime and Justice, 20, 145-264.

Maruna, S. (2001). Making good: How ex-convicts reform and rebuild their lives. Washington, DC: American Psychological Association.

McDonell, J., Strom-Gottfried, K. J., Burton, D. L., \& Yaffe, J. (2006). Behaviorism, social learning, and exchange theory. In S. P. Robbins, P. Chatterjee, \& E. R. Canda (Eds.), Contemporary human behavior theory: A critical perspective for social work ( $2^{\text {nd }}$ ed., pp. 349-385). Boston, MA: Allyn \& Bacon.

McGloin, J. M. (2009). Delinquency balance: Revisiting peer influence. Criminology, 47(2), 439-477.

Monahan, K. C., Steinberg, L., \& Cauffman, E. (2009). Affiliation with antisocial peers, susceptibility to peer influence and antisocial behavior during the transition to adulthood. Developmental Psychology, 45(6), 1520-1530.

Mulvey, E. P., Steinberg, L., Fagan, J., Cauffman, E., Piquero, A. R., Chassin, L.,... Losoya, S. H. (2004). Theory and research on desistance from antisocial activity among adolescent serious offenders. Youth Violence and Juvenile Justice, 2(3), 213236. doi: $10.1177 / 1541204004265864$

Padgett, D. K. (Ed.). (2008). Qualitative methods in social work research (2 ${ }^{\text {nd }}$ ed.). Los Angeles, CA: Sage Publications.

Paternoster, R. (1989). Absolute and restrictive deterrence in a panel of youth: Explaining the onset, persistence/desistance, and frequency of delinquent offending. Social Problems, 36, 289-309.

Piquero, A. R., Brame, R., Mazerolle, P., \& Haapanen, R. (2002). Crime in emerging adulthood. Criminology, 40(1), 137-169.

Quinn, P. D., \& Fromme, K. (2011). Alcohol use and related problems among college students and their noncollege peers: The competing roles of personality and peer influence. Journal of Studies on Alcohol \& Drugs, 72(4), 622-632.

Rebellon, C. J. (2006). Do adolescents engage in delinquency to get the social attention of peers? An extension and longitudinal test of the social reinforcement hypothesis. Journal of Research in Crime and Delinquency, 43, 387-411.

Saldana, J. (2009). The coding manual for qualitative researchers. Thousand Oaks, CA: Sage Publishing.

Sampson, R., \& Laub, J. H. (1993). Crime in the making: Pathways and turning points through life. Cambridge, MA: Harvard University Press. 
Schulenberg, J. E., \& Maggs, J. L. (2002). A developmental perspective in alcohol use and heavy drinking during adolescence and the transition to young adulthood. Journal of Studies on Alcohol, 14, 54-70.

Steinberg, L. (2008). Adolescence ( $8^{\text {th }}$ ed.). New York, NY: McGraw-Hill.

Tucker, J. S., Ellickson, P. L., Orlando, M., Martino, S. C., \& Klein, D. J. (2005). Substance use trajectories from early adolescence to emerging adulthood: A comparison of smoking, binge drinking, and marijuana use. Journal of Drug Issues, 35(2), 307-331.

Uggen, C., \& Kruttschnitt, C. (1998). Crime in the breaking: Gender differences in desistance. Law \& Society Review, 32, 399-366.

Uggen, C., \& Massoglia, M. (2002). Settling down and aging out: Desistance from crime as a separate facet of the transition to adulthood. American Journal of Sociology, 116(2), 543-582.

Warr, M. (2002). Companions in crime: The social aspects of criminal conduct. Cambridge, UK: Cambridge University Press.

White, H. R., Fleming, C. B., Min, J. K., Catalano, R. F., \& McMorris, B, J. (2008). Identifying two potential mechanisms for changes in alcohol use among collegeattending and non-college-attending emerging adults. Developmental Psychology, 44(6), 1625-1639.

White, H. R., Labouvie, E. W., \& Papadaratsakis, V. (2005). Changes in substance use during the transition to adulthood: A comparison of college students and their noncollege age peers. Journal of Drug Issues, 35, 281-306.

White, H. R., McMorris, B. J., Catalano, R. F., Fleming, C.B., Haggerty, K. P., \& Abbott, R. D. (2006). Increases in alcohol and marijuana use during the transition out of high school into emerging adulthood: The effects of leaving home, going to college, and high school protective factors. Journal of Studies on Alcohol, 67, 810-822.

Wong, M. M. (2008). Perceptions of parental involvement and autonomy support: Their relations with self-regulation, academic performance, substance use and resilience among adolescents. North American Journal of Psychology, 10(3), 497-518.

Xue, Y., Zimmerman, M. A., \& Cunningham, R. (2009). Relationship between alcohol use and violent behavior among urban African American youths from adolescence into emerging adulthood: A longitudinal study. American Journal of Public Health, 99(11), 2041-2048.

\section{Author note:}

Address correspondence to: Badiah Haffejee, MSW, University of Denver Graduate School of Social Work, 2148 S. High Street, Denver, CO 80208. Email:

Badiah.Haffejee@gmail.com 